\title{
El sistema de control de constitucionalidad en Colombia*
}

\author{
The constitutional control system in Colombia
}

Recibido: 20 de abril de 2010 - Revisado: 14 de mayo de 2010 - Aceptado: 03 de julio de 2010

Luis Javier Moreno Ortiz*

\section{Resumen}

El sistema de control de constitucionalidad en Colombia diseñado en el Acto Legislativo n. ${ }^{\circ} 3$ de 1910 es un hito dentro de una larga y fecunda tradición política y constitucional que mucho le debe a sus raíces hispanas y a sus desarrollos americanos. Tanto la acción pública de inconstitucionalidad como la excepción de inconstitucionalidad tienen claros antecedentes en el constitucionalismo de las Españas y de la Colonia; fueron elaboradas por una Asamblea Constituyente que obró con conocimiento y fidelidad a esa tradición, y han sido y son instituciones capitales de nuestro Estado social y democrático de derecho.

\section{Palabras clave}

Historia constitucional, control de constitucionalidad, acción pública de inconstitucionalidad, excepción de inconstitucionalidad y tradición jurídica hispana.

\begin{abstract}
The system of constitutional control in Colombia designed in the Legislative Act . $^{\circ} 3$ of 1910 is a milestone in a long and fruitful political and constitutional tradition owes much to his Hispanic roots and its American developments. Both the public action of unconstitutionality as the plea of unconstitutionality have clear precedents in the constitutionalism of Spain and the Colony were prepared by a Constituent Assembly acted with knowledge and faithfulness to that tradition and have been and are institutions of our capital social and democratic state of law.
\end{abstract}

Keywords

Constitutional history, constitutional review, public action of unconstitutionality, exception of unconstitutionality and Spanish legal tradition.

* Artículo resultado de investigación. ** Abogado y licenciado en filosofía y humanidades de la Universidad Sergio Arboleda. Especialista en Derecho Administrativo del Colegio Mayor de Nuestra Señora del Rosario. Magister en Derecho de la misma Universidad. Profesor investigador.

Correo electrónico:

javimor6@gmail.com 


\section{Introducción}

La centenaria Constitución Política de 1886 es la más emblemática manifestación de estabilidad jurídica en la historia republicana. Entre los vaivenes del siglo XIX, la República y la Constitución fueron maleables y cambiantes, tanto como lo eran las circunstancias propias de la época, marcadas por el conflicto, la pasión y la inmadurez de los pueblos que se formaban como una realidad independiente de aquella de la que hacían parte.

La sustitución de las constituciones caracteriza los primeros años de la República, en los que la improvisación política y constitucional, muchas veces influenciada por la adaptación de modelos extranjeros sin considerar las circunstancias de nuestra realidad, fue la regla general. A partir de la Constitución Política de 1886 se vislumbra un esfuerzo por superar esa improvisación, mediante una labor de reflexión capaz de retomar de nuestra propia tradición política y constitucional algunos elementos fundamentales, a partir de los cuales hacer nuevos desarrollos.

Durante los ciento cinco años de vigencia de la Constitución Política de 1886, los cambios se introducen sin necesidad de descartar de un tajo el orden anterior, por la vía más madura y menos traumática de la reforma. Entre las grandes modificaciones hechas a esta Constitución quizá la más importante, por sus instituciones y por la permanencia de las mismas, es la introducida por el Acto Legislativo n. ${ }^{\circ} 3$ de 1910.

El Acto Legislativo n. 3 de 1910 fue elaborado por una Asamblea Nacional Constituyente, por destacados miembros del Partido Conservador y del Partido Liberal, que se unen en un movimiento conocido como el republicanismo, con el propósito de restaurar el orden constitucional interferido y sustituido durante el gobierno del general Rafael Reyes.

Uno de los frutos más conspicuos de esa reforma es la adopción, sin restricciones, del principio de la supremacía de la Constitución. Este principio estaba reconocido, desde mucho antes, en nuestra propia tradición jurídica y en la de otras naciones civilizadas. Si bien lo que ocurre en la reforma no es algo original, esta sí aporta un sistema de control constitucional singular y propio, que es un digno desarrollo de los sistemas anteriores y que constituye un valioso aporte al constitucionalismo americano, e incluso al constitucionalismo mundial. Ese sistema está conformado por dos mecanismos de control: la acción pública de inconstitucionalidad y la excepción de inconstitucionalidad.

La acción pública de inconstitucionalidad le brinda la oportunidad a cualquier ciudadano de cuestionar la ley y, al hacerlo, de colaborar en la misión de garantizar la supremacía de la Constitución Política. Esta acción, de clara raigambre popular, es un instrumento magnífico para la democracia, pues permite al ciudadano participar en el control judicial de la legislación. La excepción de inconstitucionalidad brinda a las autoridades administrativas y judiciales la oportunidad de inaplicar las leyes que, en el caso concreto, resultan contrarias a la Constitución Política, para preservar su supremacía.

El valor y el alcance del Acto Legislativo n. ${ }^{\circ} 3$ de 1910 , y en particular del sistema de control constitucional por él establecido, no pueden examinarse sin tener en cuenta el contexto en el que surgen, en el que se aprueban y en el que se desarrollan. Al ser imprescindible el contexto, el método que hay que emplear en este caso debe ser el histórico, basado en el análisis de las circunstancias antecedentes, concomitantes $\mathrm{y}$ consecuentes a la reforma constitucional.

En las circunstancias antecedentes el análisis se remonta hasta los tiempos de Pedro II de Aragón, para mostrar que el constitucionalismo no es algo novedoso en la tradición política y jurídica de las Españas, ni un exótico descubrimiento de la República. Por esta línea se argumenta que el Acto Legislativo n. ${ }^{\circ} 3$ de 1910 es un hito histórico en la extensa y rica tradición, 
que corresponde a fundamentos propios de esta y no, a copias improvisadas de otros contextos. Este análisis está guiado por las teorías planteadas por Alfonso López Michelsen, Francisco Elías de Tejada y Miguel Malagón Pinzón; por el examen de la Constitución de 1886 y de las normas relativas a su hermenéutica, y por la revisión del gobierno de Rafael Reyes hecha por Fernando Mayorga García.

En las circunstancias concomitantes el análisis se centra en el proceso de formación del Acto Legislativo n. ${ }^{\circ} 3$ de 1910 en el seno de la Asamblea Nacional Constituyente. Se examinan las propuestas, los debates y el resultado de los mismos para argumentar que sus hacedores obraron conscientes de estar desarrollando una tradición que les era y les es propia. Este análisis está guiado por la completa historia escrita por el constituyente Lácides Segovia y por el interesante estudio de Juan Carlos Esguerra Portocarrero.

En las circunstancias consecuentes el análisis se enfoca en las primeras decisiones tomadas por las autoridades de la República, en especial la Corte Suprema de Justicia, en procesos en los cuales se pronuncia sobre la constitucionalidad de la ley o la inaplica en razón de la excepción de inconstitucionalidad, para argumentar que tanto los ciudadanos como los tribunales, desde los primeros años, hacen un uso prolijo de los instrumentos incorporados a la Constitución Política de 1886 por el Acto Legislativo n. $^{\circ} 3$ de 1910 . Este análisis está guiado por varias providencias judiciales.

\section{De Pedro II de Aragón a Rafael Reyes: los avatares de la tradición jurídica}

La desgracia del atribulado Juan sin tierra, a la sazón rey de los ingleses, tiene su momento crucial en Runnymede, cuando los altivos barones le arrancan de las manos buena parte de su poder. El rey rebajado a minúsculas, en la gramática y en la política, firma el 15 de junio de 1215 el documento que formaliza lo que los hechos establecieron: la Carta Magna. La real desgracia se extiende pronto por la cristiandad, y toca a Andrés II de Hungría, quien también debe hacer frente a sus no menos altivos nobles y termina formalizando su derrota en 1222 con la Bula de Oro.

El constitucionalismo se esmera en ver en los anteriores hechos y documentos sus más remotos antecedentes. Este discurso ha sido asumido y repetido por tirios y troyanos y se ha acuñado como un dogma. Quizá por estar pendientes de las desgracias de otros reyes, en tierras ajenas, se ha pasado por alto que en la tradición política y jurídica de las Españas hay antecedentes aún más añejos del constitucionalismo. La falta de memoria o, por qué no decirlo, la ignorancia de los hechos de nuestros antepasados, es suplida por el erudito sucesor de Jerónimo Zurita, Jerónimo de Blancas, en su imprescindible obra $\mathrm{Co}$ ronaciones de los Serenísimos Reyes de Aragón, cuyo manuscrito original es de 1585 , quien refiere que todos los reyes, desde Pedro II de Aragón, que reinó entre 1196 y 1213, hasta Fernando I de Aragón y algunas reinas, frente al Altar Mayor de la Seo de Zaragoza juraban bajo la fórmula: "Nos, que cada uno de nosotros somos igual que vos y todos juntos más que vos, te hacemos Rey si cumples nuestros fueros y los haces cumplir, si no, no".

Los antecedentes del constitucionalismo en las Españas son por lo menos tan antiguos, sino más, que sus pares en Inglaterra y en Hungría. Su desarrollo, que gira en torno de la noción de fueros y de su contrapartida: los desafueros, impregna los siglos por venir y, lo que es más importante, a las personas que viven en esa época, algunas de las cuales se lanzan con audacia a la aventura de las Américas y llegan al Nuevo Mundo, primero como conquistadores y más tarde como colonos.

No se puede pasar por alto que entre los conquistadores también hubo personas instruidas y formadas, quienes junto a los demás repli- 
carán en estas tierras las tradiciones jurídicas y políticas de sus solares nativos y de sus fueros, con la fuerza y el empeño que suelen tener las costumbres. Los duros hombres de Extremadura serán los adalides de la expedición de las Españas. El legado de bachilleres de Salamanca como Hernán Cortés o del licenciado, también de Salamanca, Gonzalo Jiménez de Quesada, cuyo talento le alcanza para fundar ciudades y al mismo tiempo refutar a mentes perturbadas como la de Jovio, en su Antijovio.

Los conquistadores, por su voluntad o en contra de ella, estarán atados al poder de los Reyes Católicos, quienes los sujetan a unas Capitulaciones, de cuya eficacia puede dar fe el propio descubridor Cristóbal Colón, que regresa a la metrópoli de uno de sus viajes cargado de grilletes y cadenas. La justicia real, ejercida por los cabildos y las audiencias, pronto se ocupará de oír y de poner remedio a los abusos.

$\mathrm{Al}$ asentarse el polvo levantado en la Conquista y al aposentarse los recién llegados en las nuevas tierras, quedándose a vivir en ellas con sus familias, bien pronto reclaman de la monarquía la provisión de jueces para tener seguridad de su honor, de su vida y de su hacienda. Así se provee por el monarca y el 17 de julio de 1549 una Audiencia se establece para el Nuevo Reino de Granada, que de esta forma se separa de la jurisdicción de la Audiencia de Santo Domingo. Con la nueva Audiencia se conforma una entidad política autónoma, de la cual surgirá después la Presidencia, el Virreinato y la República.

La creación de la Audiencia en el Nuevo Reino y sus consecuencias son juzgadas por Alfonso López Michelsen, en sus días de profesor de Historia Política y Constitucional de Colombia, como la verdadera constitución autónoma de nuestro territorio y su fecha como la de la verdadera fiesta patria. En un ensayo contenido en el libro Cuestiones colombianas afirma sin ambages:

Difícilmente podría afirmarse que con anterioridad a la fecha de la creación de la Audiencia de Santa $\mathrm{Fe}$, y más propiamente aún de la venida de los conquistadores castellanos, existiera entre nosotros Derecho alguno, público y privado. El poder de los Jefes o caciques indígenas no conocía límite alguno y se ejercitaba como un hecho de fuerza en forma arbitraria. La existencia del Derecho entre nosotros data precisamente del momento en que se adoptaron, acondicionándolas a nuestro medio, las instituciones españolas. Fue solamente cuando se les enseñó a los indios el concepto cristiano de dignidad humana cuando comenzó a concebirse el Estado como un poder limitado por derechos naturales, inherentes a la condición de criatura racional de sus sujetos. Estos mismos derechos naturales fueron los que, con criterio afrancesado $\mathrm{y}$ deficientemente enumerados, se enunciaron como derechos del hombre en nuestras Declaraciones de Independencia (p. 124).

Sobre la teoría de López Michelsen, el presidente de la Academia Colombiana de Jurisprudencia, Marco Gerardo Monroy Cabra, hace una interesante presentación en el discurso leído al conmemorar los ciento diez años de existencia de la Academia, el 23 de septiembre de 2004, como puede verse en la separata publicada con tal motivo. En su presentación, Monroy Cabra se refiere en particular a la interpretación que hace López Michelsen en su Introducción al estudio de la Constitución sobre el aforismo americano de "Se obedece pero no se cumple", para señalar que más que una forma de burlar la ley o de incumplirla, como se suele sostener por muchos, se trata de una manera de concretar el respeto por la justicia bajo unas circunstancias concretas. Para ilustrarlo cita el siguiente texto de López Michelsen, según aparece en el libro Cuestiones colombianas: 
Las leyes se obedecían, porque emanaban de una monarquía católica y obedeciéndolas se obedecía la voluntad divina. Si de Derecho se trata, obedecer a una ley porque se presume conforme con el derecho natural vale tanto como obedecerla porque cuenta con el respaldo de las mayorías. Probablemente esta concepción del derecho natural, superior a las mismas leyes positivas, es lo más valioso que nos resta del pensamiento jurídico español. No se confundió nunca en tres siglos de vigencia de las Leyes de Indias el concepto de lo justo con el concepto de lo legal. Se admitía que, aun siendo perfectas ciertas leyes, en cuanto a su origen, bien podrían ser desobedecidas por las autoridades, en razón de ese derecho natural que se impone aun al propio Monarca. Castillo de Bobadilla lo dice en su obra Política para corregidores: "Por las leyes del reino se ha establecido que las leyes y decretos contrarios a la justicia no valen y por lo tanto no deben ser ejecutados, sin que ello entrañe desacato o rebelión contra la autoridad”. Estos mismos principios se incorporaron en las Leyes de Indias, libro 2, ley 24, cuando Carlos V en Monzón les permitió a los funcionarios en las Indias abstenerse de ejecutar aquellas leyes "de cuyo cumplimiento se siga daño o escándalo irreparable" (pp. 126-127).

Los fundadores de la Nueva Granada no eran unos bárbaros, aunque en ocasiones así se comportasen algunos de ellos. Aun los menos instruidos estaban marcados por las costumbres de las Españas, en especial por sus fueros. El propio emperador Carlos V de Alemania, I de España, tendrá que batallar con dichos fueros, en su pretensión de imponer su poder sobre el de los altivos habitantes de sus reinos peninsulares. En Villalar, en 1521, las tropas imperiales desbaratan a los capitanes de la junta comunera castellana y, al hacerlo, desbaratan también la rica tradición de la que se había nutrido el éxito de sus abuelos, los Reyes Católicos.

Los destrozos causados por el emperador precipitan la decadencia del Imperio, que pasa del temido poder de Felipe II a sus decaídos epígonos, cuya dinastía sucumbe en la inanidad para ser reemplazada por los ambiciosos Borbones, seres capaces de identificarse sin disimulo con el propio Estado. Con ellos llega el absolutismo y su pretensión de controlarlo todo. La casa de los Borbón servirá de matriz a los déspotas, algunos serán ilustrados como Carlos III, otros ni siquiera ilustres como Carlos IV y Fernando VII.

Francisco Elías de Tejada y Spínola en su obra El pensamiento político de los fundadores de la Nueva Granada, de la cual me ocupo en extenso en el artículo El origen de nuestras instituciones, publicado en el número 18 del Boletín del Instituto de Estudios de Derecho de la Universidad Sergio Arboleda, presenta una esclarecedora hipótesis sobre nuestro origen institucional al sostener que:

Durante tres siglos hubo un pueblo en tierras de la actual República de Colombia que formó parte de la monarquía federativa y misionera de las Españas, nacido en el regazo de Castilla, amamantado a las leches culturales castellanas, alineado tras sus banderas en la pugna contra Europa. A los comienzos del siglo XIX ese pueblo, hasta entonces jirón de la Cristiandad antieuropea, quiso ser independiente y lo fue, pero lo fue para caer de lleno en la europeización (p. IX).

La hipótesis es muy generosa al asumir lo que ahora se conoce como República de Colom- 
bia, cae de lleno en la europeización. Si bien la República se establece a partir del denuesto de la Colonia, del renegar insensato de un pasado del que debemos hacer cargo, la huella de la tradición de las Españas es tan profunda en nuestra alma mestiza que mucho de ella queda intacta en nuestra tradición republicana, aunque nos pese o no la queramos ver. Uno de sus mejores desarrollos es, precisamente, el Acto Legislativo n. $^{\circ} 3$ de 1910.

En su empeño por saltar a la arena y batallar con aquellos que no tienen memoria o, lo que es peor, pretenden inventar un pasado que no existe sino en sus deseos, que no en su mente, De Tejada Spínola rompe una lanza, para decir, con buen sentido, que las instituciones no se forman de la noche a la mañana, que las naciones no son producto de un acto de magia y que el pasado siempre está presente, perdónese el pleonasmo, en el presente.

La independencia se hizo contra una monarquía en decadencia, gobernada, al menos en lo nominal, por el alicaído cazador que fue Carlos IV y por su ruin hijo Fernando VII. Sus validos procurarán sostener la inercia del movimiento absolutista, que se empeña en poner palos en la rueda de las autonomías hispanas, valga decir, de sus cabildos y de sus fueros. Contra eso se rebelan los americanos, sobre la base de sus cabildos y en ejercicio de sus fueros. La guerra de independencia dejará para los doctos el cadalso y para los demás la carrera militar y la gloria. Los vencedores equiparan el presente con la eternidad y se convencen de que todo ha sido siempre así, pues su memoria y sus letras no les alcanzan para ver más allá de su nacimiento. De ahí que no sea extraño que, como lo anota De Tejada Spínola:

Y así, al lograrse la independencia que la historia requería, los hombres de América volcaron contra el ayer su olvido o su desprecio y juzgaron nacer a la vida histórica en el punto de la hora independiente, sin obser- var que el cambio conseguido afectaba a un signo de la existencia colectiva, al exterior, pero no al hilo de la vida colectiva, que proseguía sin tejerse entonces. Labraron, pues, un nacionalismo que, al contraponerse legítimamente al absolutismo del siglo XVIII, por ignorar la médula tradicional común, parecía oponerse a la misma sustancia hispana. Fue un nacionalismo que, en liza contra el europeísmo borbónico, acabo en liza contra la misma tradición española, tan distinta (p. 5).

Este olvido culposo o doloso, semejante al que ocurre respecto de la edad media, envuelve a la Colonia en un vacuo y gris manto del cual nada merece la pena ser conocido. Para hacer más sencillo el olvido se acude al denuesto, cuya caricatura más señalada es el "yugo español". Basta recordar el amplio aparato de vigilancia y de control a los desafueros que monta la monarquía, en el que sobresalen clérigos, protectores de indígenas y tribunales, para constatar que el derecho y, quizá algo más importante, los derechos, no eran ajenos a estas tierras.

La primera Audiencia de la Nueva Granada, conformada por los licenciados Gutierre de Mercado, Juan López de Galarza, Beltrán de Góngora y Francisco Briceño, va a dar ejemplo de la justicia real. Ella mostrará sus dos caras, la espléndida y generosa con su primer presidente, Andrés Díaz Venero de Leiva, y la oscura y escarmentada con el oidor Juan Lavado o Montaño, hombre arbitrario y pérfido cuyos desafueros solo terminan con su degüello en Valladolid en 1561.

La audiencia y los cabildos cumplen funciones judiciales, a ellos los vecinos elevaban sus quejas y cuitas, y la mayoría de las veces obtenían satisfacción. Entre los recursos de los que disponen los vecinos se encuentra el derecho de apelar al rey, las libertades sustanciales: 
honor y hacienda, el derecho a no pagar más tributos que los libremente consentidos y el de la preexistencia del derecho castellano. No se trata pues de meros súbditos, o de algo peor: administrados, sino de personas libres, celosas de sus fueros y de sus derechos, con tribunales dispuestos a hacerlos valer. Sobre los cabildos y su tarea, De Tejada y Spínola tiene dos anotaciones que merecen la pena replicar aquí:

Fueron, pues, los cabildos en el Nuevo Reino de Granada el cauce abierto a las libertades populares. Perdido el prestigio con el poderío de las cortes en Castilla, el espíritu de libertad fuese refugiando desde el plano general al ámbito municipal. No era dable la existencia de cortes neogranadinas, porque ya habían quedado en la cuneta del caminar político las propias cortes castellanas que hubieran sido su único modelo posible; pero en los límites menores de la esfera municipal seguían cultivándose las semillas de la mejor cosecha política de libertades, fruto de viejas semillas castellanas (p. 68).

El centro vital de las nuevas entidades políticas indianas son los cabildos, integrados por los conquistadores y en los que se proyecta el espíritu de independencia de acción de los hombres de la fundación, producido por dos causas: primera, el eco de las libertades castellanas, vividas por esos fundadores desde su infancia antes de trasponer el Atlántico; y segundo, la certidumbre de que lo existente es obra de su esfuerzo, labrada con sus sacrificios y trabajos (p. 214).

Por la vía de la tradición de las Españas es posible rastrear el origen de nuestras instituciones hasta la República de Roma, como lo hacen con acierto Luisa Fernanda García López y Miguel Malagón Pinzón en su estudio Mecanismos de protección de derechos: de la República Romana a la acción pública del siglo XIX en Colombia. En este estudio se establece una interesante relación entre la intercessio romana y la acción pública de la primera República en Colombia, pasando por el derecho de veto, el justicia mayor en el Reino de Aragón y los recursos de amparo en el período colonial.

En cuanto a los recursos de amparo en el período colonial, los autores estudian la historia de México, en donde se va a consolidar bajo la República, a partir de la institución del juez de indios o naturales, que estuvo vigente entre 1592 y 1820, de la mano de Andrés Lira Guillén. Para algunos será una sorpresa, pero en realidad es una confirmación, encontrar que en ejercicio de esta institución era posible pedir amparo ante el virrey cuando se hubiera sufrido agravio, y que esta petición podía incluir la suspensión del acto reclamado y la indemnización de perjuicios. También puede sorprender el saber que el mandamiento de amparo del virrey era una orden de protección del agraviado para desfacer el entuerto o remediar el desafuero.

Vista la continuidad de la institución, no sobra reiterar el origen hispánico de nuestras instituciones, como lo hace Malagón Pinzón en sus estudios Antecedentes hispánicos del juicio de amparo y de la acción de tutela y Acción pública de inconstitucionalidad en la Colombia del siglo XIX a través de una ley sobre el Colegio Mayor del Rosario.

En el estudio de los antecedentes hispánicos, Malagón Pinzón señala el orden de prelación para aplicar el derecho castellano, conformado por la Novísima recopilación de 1805, la Nueva recopilación de 1567, las Ordenanzas Reales de Castilla u Ordenamiento de Montalvo de 1484, el Ordenamiento de Alcalá de 1348, los fueros que pudieran estar en uso y las Siete partidas de Alfonso X de 1348. En el caso de las Indias, era menester agregar otras normas, como las reales provisiones de los virreyes, los 
bandos de los gobernadores y de los virreyes, reales provisiones y autos de las audiencias, las ordenanzas de los cabildos y para los indígenas sus usos y costumbres, siempre que no sean contrarios al orden natural y cristiano. El autor, de la mano de Villapalos Salas, da cuenta con prolijidad y provecho del recurso de agravios, a cuyo texto bien merece la pena remitir a los interesados. Este amplio y prolijo conjunto normativo se completa con la garantía que tienen las personas de no ser agraviadas o de obtener remedio a los perjuicios que sufren. Esta garantía involucra incluso al rey, pues como dice Malagón Pinzón:

Con respecto a los actos contrarios a derecho, primero encontramos los actos agraviados del rey, quien al iniciar su reinado juraba respetar y guardar los derechos adquiridos de los súbditos, como privilegios, exenciones, franquezas, buenos usos y libertades. Por este acto el soberano estaba obligado a no dictar disposiciones o cartas contrarias a los fueros, y si esto llegaba a ocurrir, estas se consideraban nulas. Por ello en las cortes de Valladolid de 1293 se impuso el efecto suspensivo sobre las cartas desaforadas, para que el rey decidiera sobre ellas.

Hay que resaltar la circunstancia de las cartas contrarias a las leyes. Estas ocupan un lugar de preeminencia desde las partidas, las cortes las elaboran y solo ellas las pueden derogar, por medio de otras leyes y no por disposiciones de carácter singular. En las cortes de Burgos de 1379 , se le pide al rey que establezca una jerarquía normativa para evitar que normas singulares deroguen normas generales, y que resuelva la situación de las cartas contrarias a derecho. Frente a esta última petición el monarca respondió: "que habemos ordenado que las cartas que fueren ganadas contra derecho sean obedecidas e non complidas fasta que nos seamos requerido de ello" (p. 92).

El estudio sobre la acción pública de inconstitucionalidad, con motivo del correspondiente proceso promovido contra una ley de 1879 dictada por el Estado Soberano de Cundinamarca, mediante la cual se restringe la autonomía del Colegio Mayor de Nuestra Señora del Rosario, le brinda la oportunidad a Malagón Pinzón para desvirtuar la hipótesis de buena parte de la doctrina de que la acción pública de inconstitucionalidad fue establecida en Colombia en 1910, por primera vez en el mundo. Su hipótesis, más fiel a la realidad y a la historia, es la de que:

(...) la acción pública viene del derecho colonial español, en concreto del recurso de agravios, y que nuestro siglo XIX como heredero de esa tradición hispánica consagró la figura procesal de la acción pública desde 1811, subsistiendo este trascendental remedio durante importantes períodos históricos de dicho siglo.

Para verificar la anterior hipótesis, el autor emprende un enjundioso estudio del control de constitucionalidad bajo el régimen de la Constitución Política de 1863. Este estudio tiene como punto de partida el artículo 72 superior, conforme al cual le corresponde a la Corte Suprema suspender a pedimento del Procurador General o de cualquier ciudadano, por unanimidad de votos, la ejecución de los actos legislativos de las Asambleas de los Estados, en cuanto sean contrarios a la Constitución o a las leyes de la Unión, informando al Senado, para que este decida de manera definitiva sobre su validez. Dentro del anterior marco normativo, al estudiar el proceso de constitucionalidad de una ley del Estado de Cundinamarca, destaca 
que la Corte se abstiene de suspender la ley al no haber logrado la mencionada unanimidad, mientras que el Senado, luego de constatar que la ley es contraria a una ley federal del 18 de marzo de $1865 \mathrm{y}$ al inciso $5 .^{\circ}$ del artículo $17 \mathrm{de}$ la Constitución Política, la declara nula.

El prolijo recuento que hace Malagón Pinzón de lo establecido por muchas de nuestras constituciones durante el siglo XIX, desde la Monárquica de Cundinamarca, con su Senado de Censura y Protección, hasta la de los Estados Unidos de Colombia, con el alcance que se acaba de ver, revela que la continuidad institucional visible en la Colonia, pese a todo, se mantiene bajo la República. Esta abundante evidencia permite afirmar que el control de constitucionalidad es un tema recurrente en nuestra historia constitucional.

Mientras nuestra tradición jurídica iba del recurso de agravios a la acción pública de inconstitucionalidad, como sistemas o mecanismos idóneos para garantizar el principio de supremacía constitucional, los norteamericanos, fieles a la tradición inglesa de la que dan cuenta juristas notables como Edward Coke, encuentran en la decisión del juez John Marshall en el caso Marbury vs. Madison, en 1803, una interesante fuente para el mismo propósito. Incluso el propio Sièyes alcanza a proponer a los revolucionarios en Francia la creación de una jurisdicción constitucional, como refiero con mayor detalle en el artículo De la Jury Constitutionnaire a la Corte Constitucional, publicado en el n. ${ }^{\circ}$ 318 de la Revista de la Academia Colombiana de Jurisprudencia.

La Constitución Política de 1886 establece un nuevo orden político. En cuanto atañe a las competencias de la Corte Suprema de Justicia respecto de la constitucionalidad de la ley, la Carta la faculta en su artículo 151, numerales $4 .^{\circ}$ y $5^{\circ}$, para decidir de manera definitiva sobre la exequibilidad de actos legislativos objetados como inconstitucionales por el Gobierno y sobre la validez o nulidad de las ordenanzas departamentales que hubieren sido suspendidas , o denunciadas ante los tribunales por los interesados.

La ausencia de la ley en las materias sometidas a control de constitucionalidad no es casual ni accidental. La ley, en tanto soporte principal del orden, que es la principal preocupación de la regeneración, no puede ser cuestionada, sino que debe ser cumplida. Eso se deja claro en la Ley 153 de 1887, cuya parte primera contiene las reglas generales sobre la validez y aplicación de las leyes, valga decir, sobre la hermenéutica jurídica del nuevo orden. En su artículo $6 .^{\circ}$, la ley establece una presunción de derecho de constitucionalidad de la ley, conforme a la cual una ley posterior a la Constitución se reputa constitucional y se aplicará incluso cuando parezca contraria a ella. Si la constitucionalidad de la ley se presume, no es posible considerar acciones encaminadas a cuestionar o a desvirtuar dicha constitucionalidad.

El antecedente político más próximo al Acto Legislativo n. ${ }^{\circ} 3$ de 1910 es el gobierno del general Rafael Reyes. Un gobierno que empieza con un flagrante fraude electoral, como refiere con detalle Lácides Segovia, en compañía de otros hombres honorables en un documento llamado Explicación necesaria. Sobre lo acaecido en estos singulares años se puede consultar con provecho el revelador estudio Las reformas constitucionales del período de Reyes, de Fernando Mayorga García, que aparece en el tomo II del libro Historia constitucional de Colombia.

De los hechos de Reyes quizá el más significativo fue el uso que le dio al estado de sitio. Con base en el artículo 121 de la Constitución de 1886, el Presidente hizo casi todo cuanto quiso, desde convocar a una Asamblea Nacional Constituyente y Legislativa hasta cerrar el Congreso hasta nueva orden. Esta asamblea de amigos del régimen hará varias enmiendas a la Constitución. Una de las más controvertidas es la que se introduce en el Acto Legislativo n. ${ }^{\circ} 4$ 
de 1905, que modifica el artículo 204 de la Carta, y que dispone en su artículo $5^{\circ}$ :

El período presidencial en curso, $\mathrm{y}$ solamente mientras esté a la cabeza del gobierno el Sr. general Reyes, durará una década, que se contará del $1 .^{\circ}$ de enero de 1905 al 31 de diciembre de 1914.

En el caso de que el Poder Ejecutivo deje de ser ejercido definitivamente por el Sr. general Rafael Reyes, el período presidencial tendrá la duración de cuatro años para el que entre a reemplazarlo de una manera definitiva; esta duración de cuatro años será también la de todos los períodos subsiguientes.

El uso poco ortodoxo del estado de sitio y de las normas por parte de la Asamblea Constituyente y Legislativa y por el presidente Reyes, motiva una reacción entre los principales líderes de los partidos políticos, quienes se comprometen en un propósito monumental e inaplazable: recuperar la República. Ese movimiento se llamará republicanismo y será el principal hacedor y responsable del Acto Legislativo n. ${ }^{\circ} 3$ de 1910.

\section{La historia contada por uno de sus protagonistas: el proceso de formación del Acto Legislativo n. 3 de 1910}

En su ya clásica Historia de las leyes. Acto Legislativo número 3 de 1910, Lácides Segovia ofrece una muy esmerada relación de los hechos y de las actuaciones que rodean el quehacer de la Asamblea Nacional Constituyente que elaboró esa reforma constitucional. En los párrafos siguientes se recrea esa historia de la mano de esta útil obra.

La Asamblea fue convocada por el Presidente de la República por medio del Decreto 126 del 25 de febrero de 2010, en ejercicio de las facultades que le confiere el Acto Legislati- vo . $^{\circ} 9$ de 1905, y se instaló el 15 de mayo de ese mismo año. El discurso del presidente Ramón González Valencia en el acto de inauguración de labores de la Asamblea es premonitorio y acertado. Dice el Presidente:

\begin{abstract}
Abrigo el convencimiento de que este acto alcanzará en la historia de Colombia la importancia de un suceso fausto y memorable, porque no hay duda de que está llamada a dejar huella de luz una corporación como esta, constituida por la voluntad consciente de los pueblos; formada por egregios ciudadanos que con sus talentos, virtudes cívicas y servicios prestados a la Patria han sabido conquistar un nombre ilustre, y que dignamente representan las distintas tendencias políticas que actualmente se hacen sentir en la Nación; reunida, en fin, en la época del Centenario, esto es, en los días más propicios para que el amor patrio se levante a su mayor altura y para que el corazón de los colombianos palpite a un impulso de los más excelsos ideales (p. 47).
\end{abstract}

En la propia sesión de instalación de la Asamblea, el diputado Nicolás Esguerra presenta un proyecto de reforma a la Constitución con estas palabras:

La labor que hoy tiene en sus manos la Asamblea Nacional, en materia de reformas constitucionales, está encerrada en límites estrechos, debido a que aún nos envuelven las redes que tejió el Gobierno del Quinquenio para apresar las libertades públicas, y que debieron desde el año pasado destruirse, anulando todos los actos reformatorios de la Constitución, expedidos por el Poder Legislativo, de creación del presidente señor general Reyes (p. 50). 
En los trabajos de la Asamblea se da un interesante debate, por lo que involucra y por lo que resulta de él, entre los diputados Esguerra y Holguín y Caro. El primero, el mismo día de la instalación de la Asamblea, presenta un proyecto de reforma que, en lo relativo al Título XV sobre la Administración de Justicia, en el artículo 24, introduce la acción pública de inconstitucionalidad en los siguientes términos:

A la Corte Suprema de Justicia se le confía la guarda de la integridad de la Constitución.

En consecuencia, además de las facultades que le confieran esta o las leyes, tendrá las siguientes:

Decidir definitivamente sobre la exequibilidad de los actos legislativos que hayan sido objetados como inconstitucionales por el Gobierno, o sobre la de las leyes o decretos acusados ante ella por cualquier ciudadano como inconstitucionales, previa audiencia del Procurador General de la Nación.

El 18 de mayo de 1910 el proyecto es aprobado en primer debate con el voto afirmativo de 35 representantes y el voto negativo de los diputados Mesa y Rosas. Mientras avanza este proyecto, se discute el del diputado Holguín y Caro, quien propone reformar el Título $\mathrm{XV}$ en los siguientes términos:

Corresponde a la Corte Suprema suspender, para cada caso particular, a solicitud de la parte agraviada y con audiencia del Procurador General, el efecto de las leyes que vulneren los derechos civiles garantizados por el Título III de la Constitución (p. 76).

El 11 de junio se presenta el informe de la Comisión que estudió el proyecto de Esguerra, conformada por los diputados Clemente Salazar M., Guillermo Quintero C., Hernando Holguín y Caro, Carlos José Espinosa y Gonzalo Pérez, quienes solicitan se dé segundo debate al proyecto con algunas modificaciones. En lo pertinente, la modificación corresponde de manera íntegra a lo propuesto por el diputado Holguín y Caro.

Luego de múltiples y variadas discusiones en torno de la pena de muerte, el 19 de septiembre los diputados se ocupan de debatir sobre lo que luego serán los artículos 40 y 41 del Acto Legislativo. El diputado Rodríguez propone atemperar la fórmula de 1863 con las nuevas circunstancias, para decir:

La Corte Suprema de Justicia, a solicitud de cualquier ciudadano y con audiencia del Procurador General de la Nación, suspenderá las leyes inconstitucionales y pasará su resolución al Congreso; para que decida sobre su validez.

Luego de escuchar a los diputados Holguín y Caro, Esguerra y Rosas, la anterior propuesta es negada el 20 de septiembre. En su lugar, Holguín y Caro propone:

En las controversias judiciales, y en caso de incompatibilidad manifiesta entre la Constitución y una disposición legal, se aplicará lo dispuesto en la Constitución; pero toda decisión en tal sentido habrá de ser consultada con la Corte Suprema.

$\mathrm{Si}$ la incompatibilidad no fuera manifiesta, se aplicará la ley en el sentido más conforme con lo que la Constitución preceptúe.

En ese estado de la discusión, el diputado Guillermo Quintero recordará el artículo 6. ${ }^{\circ} \mathrm{de}$ la Ley 153 de 1887, que establece la presunción de constitucionalidad de la ley. Ante lo anterior el diputado Salazar M. propone, con el apoyo del diputado Arbeláez, retomar el texto presentado por el diputado Esguerra. Esta propuesta 
es votada negativamente por los diputados Holguín y Caro, Mesa y Perilla, pero acaba siendo aprobada a la postre por la Asamblea. Los textos definitivos de los artículos 40 y 41 son los siguientes:

Artículo 40.- En todo caso de incompatibilidad entre la Constitución y la ley se aplicarán preferencia las disposiciones constitucionales. Artículo 41.- A la Corte Suprema de Justicia se le confía la guarda de la integridad de la Constitución.

En consecuencia, además de las facultades que le confieren esta y las leyes, tendrá la siguiente:

Decidir definitivamente sobre la exequibilidad de los Actos Legislativos que hayan sido objetados como inconstitucionales por el Gobierno, o sobre todas las leyes o decretos acusados ante ella por cualquier ciudadano como inconstitucionales, previa audiencia del Procurador General de la Nación.

Juan Carlos Esguerra Portocarrero, en su destacado ensayo 'La reforma constitucional de 1910', que aparece en el libro Historia Constitucional de Colombia, al referirse al control de constitucionalidad existente antes de esta reforma, reconoce:

Es verdad que, según ese sistema, había un control jurisdiccional y una decisión de exequibilidad, pero no lo es menos que se trataba de un control harto limitado, ya que el dueño único de la llave era el Presidente, como que solo él podía objetar el proyecto de ley, de modo de darle paso a la posibilidad de que, si el Congreso insistía, la Corte quedaba habilitada para entrar a ocuparse del tema y para pronunciarse definitivamente sobre la constitucionalidad o inconstitucionalidad.
Sin objeción del Presidente, el proyecto se convertía en ley y esta ya no sería revisable o anulable.

Luego de referir en detalle el origen de la norma, Esguerra Portocarrero resalta lo que quizá sea el mayor valor de la acción pública de inconstitucionalidad, su condición de pública y de popular, su capacidad de poner en manos de cualquier ciudadano el poder de enfrentarse, en defensa de la Constitución, con el Congreso, al someter la ley a juicio. Y esto, que sin duda es audaz, ocurre poco tiempo después de considerar que la ley, merced a una presunción de derecho, se reputa constitucional.

\section{La apropiación de las instituciones: experiencias de participación de ciudadanos y jueces en la acción y en la excepción}

La supremacía de la Constitución, asegurada de manera irreversible por el Acto Legislativo n. ${ }^{\circ} 3$ de 1910 , será reafirmada por la Corte Suprema de Justicia en un interesante auto del 17 de agosto de 1911, en el cual resuelve que no hay lugar a decidir sobre la inexequibilidad del artículo $6 .^{\circ}$ de la Ley 153 de 1887, que establecía la presunción de constitucionalidad de la ley. La mera existencia de una demanda por medio de la cual se ejerce la acción de inconstitucionalidad contra la mencionada norma, revela lo tortuoso y lo profundo del cambio introducido. Para resolver la cuestión, la Corte se vale de la hermenéutica contenida en la Ley 153 de 1887, para establecer la inconstitucionalidad sobreviniente del precepto demandado. Con una concisión digna de emularse, dice la Corte:

Dados los términos en que están concebidos los preceptos legales transcritos, y muy especialmente el artículo 9..$^{\circ}$ de la Ley 153 de 1887, resulta claramente que el artículo $6 .^{\circ}$ de la misma Ley, como anterior al 40 del Acto reformatorio número 3 de 1910, y como contrario a este 
en su letra, en su espíritu, debe considerarse insubsistente, y por lo tanto, sin que pueda producir efecto. El artículo 41 del mismo Acto reformatorio, el que hoy hace parte de la Constitución Nacional, que confiere a la Corte la facultad de decidir sobre la inexequibilidad de los Actos legislativos objetados como inconstitucionales, o sobre las leyes acusadas ante ella por cualquier ciudadano como contrarias a la Constitución, parte necesariamente de la base de que estas últimas se hallen produciendo sus efectos, como mandatos emanados del Poder que, según la Carta Fundamental, puede expedirlos.

Merece la pena traer a cuento, para ilustrar la experiencia de ciudadanos y de jueces en dos casos interesantes: las objeciones al proyecto de ley que concede unos auxilios al municipio de Ambalema y la demanda que se presenta contra la Ley 14 de 1914, por medio de la cual se aprueba el tratado celebrado entre la República de Colombia y los Estados Unidos de América, sobre el reconocimiento de la independencia de Panamá.

En el primer caso, el Congreso decreta un auxilio al municipio de Ambalema, por haber ocurrido en él una serie de incendios que ha dejado muchos damnificados. El Presidente objeta el proyecto de ley porque, al tenor del artículo 78.5 de la Carta, le está prohibido al Congreso y a cada una de sus Cámaras decretar a favor de personas o entidades, gratificaciones, indemnizaciones, pensiones $u$ otras erogaciones que no estén destinadas a satisfacer créditos o derechos reconocidos con arreglo a una ley preexistente, salvo lo dispuesto en el artículo 76.18.

En Sentencia de Sala Plena del 3 de noviembre de 1911, la Corte, antes de resolver el caso, advierte con buen sentido que su tarea debe limitarse a estudiar el asunto y fallarlo, "situándose en el terreno del derecho estricto, y haciendo a un lado todo sentimiento que pudiera extraviarla de la recta interpretación del mandato constitucional". Al asumir este estudio, la Corte encuentra que además de la prohibición constitucional existe una ley, la Ley 18 de 1890, que faculta al Congreso para conceder auxilios por causa de calamidades públicas. Se presenta, pues, un conflicto entre dos normas jurídicas: la Constitución y la ley. La Corte resuelve este conflicto aplicando el artículo 40 de la Carta, que establece la excepción de inconstitucionalidad, lo que la lleva a inaplicar la disposición legal. Son sus palabras:

De igual modo que la expresada Comisión del Senado, el señor Procurador general es de concepto que las objeciones aducidas por el señor Presidente de la República deben tenerse por infundadas mientras subsista la facultad que otorga al Congreso la precitada Ley 18 de 1890. Con todo, semejante doctrina, que fue jurídicamente correcta y de estricta observancia hasta ayer no más, en fuerza del derogado artículo 6. ${ }^{\circ}$ de la Ley 153 de 1887 , es de todo punto inaceptable en la actualidad, porque ella está en abierta contradicción con el principio fundamental consignado en el artículo $40 \mathrm{del}$ Acto legislativo número $3 \mathrm{de}$ 1910, que manda aplicar de preferencia las disposiciones constitucionales en todo caso de incompatibilidad entre la Constitución y la ley. Por lo demás, conviene advertir que para las objeciones a que se alude no se ha invocado la simple ilegalidad del proyecto mencionado, sino su repugnancia con un precepto constitucional, en uno de los dos casos en que al Presidente de la República le está permitido oponer su veto a los proyectos de leyes adoptados por el Congreso y 
sometidos a la sanción del Poder Ejecutivo; de donde claramente se deduce que el punto que se discute ha de ser estudiado y decidido a la sola luz de la Carta Fundamental, y haciendo abstracción completa de las leyes ordinarias discordantes con ella, una vez que estas no pueden prevalecer en manera alguna sobre aquella, sin que lógicamente resulte poco menos que ilusoria la atribución presidencial conferida a este respecto.

De esta decisión salvarán su voto los magistrados Manuel José Angarita, Tancredo Nannetti y Rodríguez P.

Este precedente será reiterado por la Corte en Sentencia de Sala Plena del 4 de diciembre de 1913, en la cual declara inexequible un proyecto de ley por medio del cual el Congreso concede un auxilio al municipio de Chiriguaná, cuyas construcciones habían sido destruidas en una parte considerable por un incendio.

En el segundo caso, el tratado celebrado entre la República de Colombia y los Estados Unidos brinda la oportunidad a un ciudadano, el señor Carlos José Espinosa, de acusar como inconstitucional la Ley 14 de 1914. La novedad de la institución se advierte en la circunstancia de que el actor anexa a la demanda una serie de pruebas, entre las cuales se destaca la copia auténtica de la ley y, para abundar en evidencias, un ejemplar del diario oficial en el que esta aparece publicada. Antes de analizar sus argumentos, vale la pena recordar la acertada advertencia del Procurador General de la Nación, quien dice:

Creyendo ejercitar el derecho que da el artículo 41 del Acto legislativo número 3 de 1910, y demandando en apariencia la inexequibilidad de la Ley 14 del presente año, lo que el señor general Carlos José Espinosa pide, en realidad, es que se decida por vosotros la inconstitucionalidad del proyecto de tratado entre Colombia y los Estados Unidos. Yo os daré con mucho gusto mi concepto sobre el fondo del extenso y razonado memorial del señor general Espinosa, cuando hayáis decidido por auto ejecutoriado que la Corte Suprema de Justicia tiene facultad constitucional o legal para intervenir en la hechura de tratados públicos de la manera ideada por el señor general Espinosa, o de cualquier otra manera, y que un fenómeno jurídico en potencia imperfecto o incompleto puede ofrecer materia de acciones judiciales. Antes de dictarse esa decisión, mi trabajo carece de objeto.

El señor Espinosa no será el único ciudadano que intentará someter las leyes aprobatorias de los tratados internacionales, y los propios tratados, al control de constitucionalidad por la vía de la acción pública, pero el hecho de haya sido uno de los primeros en hacerlo, constituye un interesante precedente en nuestra historia constitucional. De los 15 cargos planteados por el actor, fiel a nuestra mala costumbre de pensar que el resultado es proporcional a lo desmedido del esfuerzo, se puede destacar que la mayoría de ellos en realidad atacan el tratado y no la ley. Ante el malestar que le causa al actor, y a buena parte de la opinión de entonces, que la República de Colombia reconociera la independencia del antiguo Departamento de Panamá, su extenso y repetitivo discurso se construye a partir de una de las nociones más repetidas, y quizá más dañinas, en nuestra tradición política y constitucional: la de la soberanía, en especial en cuanto atañe a la integridad territorial y al honor nacional. En ese reproche se consumen los primeros diez cargos. En los restantes se anticipa el manido discurso de que el tratado vulnera la esencia de la Constitución, algo así como su espíritu; se reafirma la competencia de la Corte para cono- 
cer de la demanda, lo cual no es en sí mismo un cargo, pero así suelen ser los ciudadanos y está bien que así sea; se infiere, de manera curiosa, que la inconstitucionalidad del tratado es la causa de la inconstitucionalidad de la ley, y no a la inversa, como parecía al comienzo.

Al estudiar el caso, la Sala Plena de la Corte Suprema, en Sentencia del 6 de julio de 1914, se centra en el problema de establecer su propia competencia, a partir de la especial naturaleza que tiene la ley aprobatoria de un tratado. Para ello recuerda que si bien el artículo 41 del Acto Legislativo n. 3 de 1910 dice que la acción procede respecto de "todas las leyes", sin excepciones y, por tanto, en principio la Corte sí tendría competencia para conocer de la demanda, con buen sentido jurídico precisa que esta ley tiene una serie de características que la diferencian de las demás. Son sus palabras:

Aun cuando la ley que aprueba un tratado público esté sometida en su formación a los requisitos ordinarios que presiden la expedición de los actos legislativos comunes, no puede revocarse a duda que, por otros aspectos, difiere sustancialmente de las leyes ordinarias. Estos son actos unilaterales, expresión de voluntad del soberano que manda, prohíbe o permite, y que se cumplen con solo el requisito de su sanción y promulgación. Aquella es elemento de un acto jurídico complejo, es la manera como una de las altas partes contratantes manifiesta su consentimiento a las estipulaciones de un pacto sinalagmático internacional, no establece por sí sola relaciones de derecho, y su eficacia depende del consentimiento de la otra nación contratante, si esta por su parte ratifica las cláusulas convenidas por sus negociadores. La ley que aprueba un tratado público tiene, pues, un carácter especial.
El perspicaz razonamiento de la Corte le sirve para advertir que si bien la ley viene a ser un elemento necesario del tratado, "no por eso puede lógicamente confundirse el pacto con la ley que lo aprueba", pues el tratado "contiene las estipulaciones recíprocas de las partes, los deberes que contrae cada una de ellas y los derechos que adquiere, y no surge a la vida jurídica sino cuando las potestades supremas contratantes lo han ratificado y se han canjeado las ratificaciones". Así las cosas, al cuestionarse en realidad la constitucionalidad del tratado y no de la ley, la Corte encuentra que no tiene

Según la Constitución, facultad ninguna para resolver si han de subsistir o no las estipulaciones acordadas, porque no es de su incumbencia el conocimiento de tratados públicos. Menos aún podría la Corte declarar la inconstitucionalidad del Tratado, después del canje de las ratificaciones; porque, siendo un acuerdo de voluntades entre los dos Estados, no sería dable que uno solo de ellos, aun por medio de su más alto Tribunal, desatase el vínculo contraído, que a tanto equivaldría declarar inconstitucional y por lo mismo sin fuerza obligatoria la ley que lo aprobó. Según esto, por más que el artículo 41 del Acto legislativo reformatorio de la Constitución hable, en términos generales de que a la Corte Suprema corresponde decidir definitivamente sobre todas las leyes o decretos acusados ante ella por cualquier ciudadano, como inconstitucionales, si de la aplicación del tenor literal de este precepto se llega a conclusiones que abiertamente hieran otros cánones fundamentales de la Carta, la jurisprudencia y la más sana crítica forense imponen el no darle a aquel precepto mayor alcance que el que debe tener para llenar su fin, que es el de guardar la 
integridad de la Constitución. En tal virtud, si conforme al artículo $57 \mathrm{del}$ Estatuto, todos los poderes públicos son limitados y ejercen separadamente sus respectivas atribuciones; si de acuerdo con el artículo 34 del Acto legislativo n. ${ }^{\circ} 3$ de 1910 , reformatorio de la Constitución, corresponde al Presidente de la República celebrar con potencias extranjeras tratados y convenios que se someterán a la aprobación del Congreso; si según el numeral 20 del artículo 76 de la Carta corresponde al Poder Legislativo aprobar o desaprobar los tratados que el Gobierno celebre con potencias extranjeras; si la misma Constitución no le ha dado al Poder Judicial ingerencia en la formación de tratados públicos; y por último, si a la luz de elementales principios no puede admitirse que la validez y eficacia de los pactos internacionales queden sujetas, y sobre todo sujetas de modo indefinido, a la decisión de una sola de las altas partes contratantes, es forzoso deducir que la Corte no puede acceder a la demanda promovida contra el Tratado de 6 de abril del año en curso, por carecer de facultades para ello. Compete a la Corte Suprema la guarda de la integridad de la Constitución, y no sería mantener esa integridad el romper con la armonía que existe y debe existir entre sus diferentes partes.

Pese a la circunstancia de que casi la mitad de los magistrados salvará su voto, es indudable que la Corte razona con buen juicio, que su discurso está hilvanado con esmero y es verosímil, y que es capaz de hacerlo de manera breve y sintética.

Este somero recuento de los primeros ejercicios de la acción pública de inconstitucionalidad y de la excepción de inconstitucionali- dad, en los primeros años de estas instituciones, revela el alcance y la calidad de las actuaciones de nuestros ciudadanos y de nuestras autoridades, y marca una tendencia que se ha mantenido, pese a todo, hasta nuestros días, como puede advertirlo cualquier lector desprevenido que mire las demandas que se presentan hoy y las decisiones que generan, así con los años, en especial los últimos, se haya perdido el aprecio de la judicatura por la brevedad y la síntesis.

\section{Conclusiones}

El sistema de control constitucional colombiano diseñado en el Acto Legislativo n. ${ }^{\circ} 3$ de 1910 es un hito dentro de una larga y fecunda tradición política y constitucional que mucho les debe a sus raíces hispanas y a sus desarrollos en América.

El completo y complejo sistema de control constitucional colombiano, un siglo después, funciona como en sus primeros años, y sigue contribuyendo a consolidar las instituciones jurídicas republicanas y la democracia. Ese es el legado de aquellos hombres que pusieron por encima de sus intereses particulares los de la República, y que formaron un movimiento que fue llamado con razón y con justicia republicanismo.

El asumir sin timidez el principio de supremacía de la Constitución, en tiempos en los cuales el culto a la ley todavía era una religión mayoritaria, ha contribuido a preservar la civilidad y la civilización de la República, a pesar de los muchos y muy complejos desafíos a los que ha sido menester hacer frente en las últimas décadas.

En la República de Colombia los ciudadanos, cualquiera de ellos, incluso el más humilde y carente de ilustración, tienen en sus manos el inmenso poder de someter a juicio a la ley y al Congreso. Este matiz popular, en el mejor de los sentidos, del constitucionalismo colombiano, consolida y refuerza la democracia participativa. 


\section{Referencias}

Doctrinales:

De Blancas, J. Coronaciones de los Serenísimos Reyes de Aragón. Manuscrito de 1585, impreso en Zaragoza por Diego Domer, en el año de 1641.

De Tejada y Spínola, F.(1955). El pensamiento político de los fundadores de la Nueva Granada. Publicaciones de la Escuela de Estudios Hispano-Americanos de la Universidad de Sevilla: Colección 'Mar adentro'. Sevilla.

Esguerra Portocarrero, J. (2010). 'La reforma constitucional de 1910', en Historia constitucional de Colombia. Siglo XX. Bogotá, Academia Colombiana de Jurisprudencia.

García López, L. y Malagón Pinzón, M. (2009). 'Mecanismos de protección de derechos: de la República Romana a la acción pública del siglo XIX en Colombia', revista Opinión Jurídica, Vol. 8 n. ${ }^{\circ} 16$. Medellín, Universidad de Medellín.

Jiménez de Quesada, G. (1952). El antijovio. Bogotá, Instituto Caro y Cuervo.

López Michelsen, A. (1955). Cuestiones Colombianas (Ensayos). México D.F., Impresiones Modernas S.A.

Malagón Pinzón, M. (2003). 'Antecedentes hispánicos del juicio de amparo y de la acción de tutela', Revista Estudios SocioJurídicos. Bogotá, Colegio Mayor de Nuestra Señora del Rosario. Y 'Acción pública de inconstitucionalidad en la Colombia del siglo XIX a través de una ley sobre el Colegio Mayor del Rosario', Revista Estudios Socio-Jurídicos, Vol. 9, n. ${ }^{\circ}$ 2. (2003). Bogotá, Colegio Mayor de Nuestra Señora del Rosario.
Mayorga García, F. (2010). 'Las reformas constitucionales del período de Reyes en $\mathrm{La}$ reforma constitucional de 1910', en Historia Constitucional de Colombia. Siglo XX.Bogotá, Academia Colombiana de Jurisprudencia.

Monroy Cabra, M. (2004). 110 Aniversario de la Academia. Septiembre 23 de 18942004. Bogotá, Academia Colombiana de Jurisprudencia.

Segovia, L. (2010). Historia de las Leyes. Acto Legislativo Número 3 de 1910. Bogotá, Academia Colombiana de Jurisprudencia. Y, junto con otros autores, Explicación necesaria, publicación del 18 de diciembre de 1904.

\section{Normativas:}

Constitución de Cundinamarca de 1811.

Constitución de los Estados Unidos de Colombia de 1863 .

Ley federal del 18 de marzo de 1865.

Constitución Política de 1886.

Ley 153 de 1887.

Ley 18 de 1890.

Acto Legislativo n. ${ }^{\circ} 4$ de 1905.

Acto Legislativo n. ${ }^{\circ} 9$ de 1905.

Decreto legislativo 126 de 1910.

Acto Legislativo n. ${ }^{\circ} 3$ de 1910.

Ley 14 de 1914.

Jurisprudenciales:

Auto de la Sala Plena de la Corte Suprema de Justicia del 17 de agosto de 1911. 
Sentencia de la Sala Plena de la Corte Suprema de Justicia del 3 de noviembre de 1911.

Sentencia de la Sala Plena de la Corte Suprema de Justicia del 4 de diciembre de 1913.

\section{Sentencia de la Sala Plena de la Corte Suprema} de Justicia del 6 de julio de 1914. 